\title{
Cost Comparison of Emergency Cesarean Section in Indonesia: The impact of Australian Model of Diagnosis-related Groups as a Payment System for Patient Care in Hospitals
}

\author{
Sitti Rahmawati ${ }^{1 *}$, Mark A. Graber ${ }^{2}$, Mohammad Hakimi $^{3}$, Ali Ghufron Mukti ${ }^{4}$ Indra Bastian ${ }^{5}$, Nurulhuda Rahman ${ }^{6}$ \\ ${ }^{1}$ Department of Economics and Business, Tadulako University, Palu, Indonesia; ${ }^{2}$ Department of Family and Emergency \\ Medicine, Faculty of Medicine, Clinic and Hospital of University of lowa, United States; ${ }^{3}$ Department of Clinical Epidemiology \\ and Biostatistics, Faculty of Medicine and Health, Gadjah Mada University, Yogyakarta, Indonesia; ${ }^{4}$ Department of Public \\ Health, Faculty of Medicine and Health, Gadjah Mada University, Yogyakarta, Indonesia; ${ }^{5}$ Department of Accounting, Faculty \\ of Economics and Business, Gadjah Mada University, Yogyakarta, Indonesia; ${ }^{6}$ Depatment of Statistics, Faculty of Mathematics \\ and Natural Science, Tadulako University, Palu, Indonesia
}

Edited by: Sasho Stolesk Citation: Rahmawati S, Graber MA, Hakimi M, Mukti AG, Bastian I, Rahman N. Cost Comparison of Emergency Model of Diagnosis-Related Groups as a Payment System for Patient Care in Hospitals. Open Access Maced $J$ Med Sci. 2021 Mar 08: 9(E):216-223 https://doi.org/10.3889/oamjms.2021. 5831

Keywords: Sustainable development goals; Cesarean section; Diagnosis-related groups; Costs Correspondence: Sitti Rahmawati, Department of Economics and Business, Tadulako University, Palu, Central Sulawesi, Indonesia. E-mail: siti131962@gmail.com Received: 02-reb-202 Accepted: 25 -Feb-202

Copyright: () 2021 Sitti Rahmawati, Mark A. Graber, Mohammad Hakimi, Ali Ghufron Mukti, Indra Bastian, Nurulhuda Rahman Funding: The LPPM of Tadulako University financially
supports the publication of this article Competing Interest: The authors have declared that no competing interest exists. Open Access: This is an open-access article distributed (C)

\begin{abstract}
BACKGROUND: The cesarean section in Indonesia was higher, still worrying for women and babies' health with pregnancy complications. It will have psychological effects such as trauma and stress during labor and its consequences on labor cost.

AIM: This study's purpose was to determine the cost of cesarean delivery as a diagnosis of transition-related groups and the Australian-diagnosis-related groups (AR-DRGs) model's impact.

METHODS: The research method is descriptive qualitative study. The 42 samples are pregnant women and that selected by purposive sampling. The data are collected from a secondary data source of medical record installations, observations, interview interviews, and focus group discussion with health professionals, nurses, doctors, and midwives. Data analysis is based on the activity-based costing system method. It includes cost treatment per disease diagnosis, cesarean section AR-DRG 370 method as a payment method for hospital treatment.

RESULTS: Determinants of cost differences in cesarean section surgery are based on AR-DRG 370 related to diabetes and eclampsia (complications and comorbidities) with relatively high-cost rates of O01A DRGs of US\$2639 due to high-risk pregnancy complications. Complications of mild pregnancy (DRGO01D) with different categories of uterine rupture and sepsis have a low-cost average at the total cost of US\$1251. Payment ability of an average of 42 respondents shows the costs category of DRGs O01A-DRGs O01D US\$ 7088 or US\$169, per patient and length of stay 4-6 days.

CONCLUSIONS: The impact of Australia's AR-DRGs model of transition DRG prospective payment shows that the health system can improve the quality of professional services in hospitals and control costs, and labor costs are cheaply profitable for hospitals. The results are accurate and experienced to be applied in Indonesian hospitals.
\end{abstract}

\section{Introduction}

The Sustainable Development Goals (SDGs) were conducted from 2015 to 2030 [1], [2], [3]. Births by cesarean section are increasing in the world [4]. The number of women who deliver babies by cesarean section has almost doubled. This procedure can be done if needed, with the health condition of mother and baby as a consideration because it causes complications and side effects for both mother and baby - the high rate of cesarean delivery worries more every year. Recent research shows that the rate of cesarean delivery has almost doubled and the quality of cesarean deliveries has almost doubled from 2000 to 2015 [5], [6]. Use of the cesarean section was $12 \%$ of total births to $21 \%$ in 2015 . The highest was $58.1 \%$ occurred in the Dominican Republic. The study by Lancet medical journal analyzed the data on 169 countries owned by the WHO and UNICEF [7]. The study found that $60 \%$ of countries use the fault method, and $25 \%$ cannot do it as needed. Experts estimate that $10-15 \%$ of medically delivered births require cesarean section treatment due to complications such as bleeding, hypertension, or abnormal baby position [8], [9].

Higher cesarean section mostly occurs in wealthy people who use it for non-medical purposes, and this needs concern because it is risky for the mother and child. Brazil and China use the cesarean method for low-risk pregnancies, women with high education, and women who have previously had a cesarean [10], [11]. Women in China, America, Europe, and ASEAN show a higher cesarean section from year to year with expensive labor costs, but women prefer cesarean delivery than expected delivery [12]. Fifteen countries, including Mexico and Cuba, have cesarean section rates of up to $40 \%$ in 2016. The economic consequences of cesarean section for women in the United States are done with insurance. 
The cesarean section is a typical operation performed in the United States on women at high risk [13], [14].

Indonesia promotes doctors and midwives to play an essential role in achieving the third target of SDGs, especially related to women cesarean section and safety of mothers and babies [15], [16]. The infant mortality rate decreased by $68 / 100,000$ births in 1991 to $32 / 100,000$ births in 2012. However, maternal mortality rates (MMR) and births mortality were still high in 2012. It increased from 228 to $359 / 100,000$ births and decreased to $305 / 100,000$ live births in 2019 . It means 305 women die every 100,000 births in Indonesia. Malaysia has reduced the MMR by $45 \%$ in the past 20 years. Efforts were made to reduce MMR to be together with primary, secondary, and tertiary health services to support Indonesian women in preventing unwanted pregnancies and saving the lives of babies born in cesarean delivery. Driving factors the cesarean section is characteristic of mother and her age with complications of pregnancy [17], [18]. The prevalence of women delivery in cesarean section in Indonesia is around 6.5\% [19].

Central Sulawesi is above the national average of $19.9 \%$ in cases of cesarean section. Inefficient procedures for an extended length of stay cause a long waiting list. The community needs fair quality service cost and control. The Australian diagnosisrelated groups (AR-DRGs) 370 model as a payment system for patient care in hospitals can minimize the cost of cesarean section [20], [21]. Female birth rates in cesareans in Indonesia have risen sharply and caused public health problems in Indonesia [22]. Researchers also found common reasons for women asking for cesarean methods, including past bad experiences, fear of pain during normal labor, and decreased normal function [23], [24], [25].

\section{Literature Review}

Theory of Health Economics was health economic evaluation as the comparative analysis of alternative action costs and consequences [26]. It differs from other forms of study because both prices and values are relative as resources consumed health-care program and health improvement. The approach has the same three stage process for the assessment of all costs and benefits. All relevant expenses and benefits must be (1) identified, (2) quantified, and (3) valued. The cost of health services is very closely related to DRG to diagnose the patient's disease. DRGs Australia is a way to identify patients with the same needs and resources in the hospital, then grouped in the same disease group. Therefore, the payment of hospital care based on DRGs is a way to pay hospital treatment based on diagnosis, not based on the utilization of medical and non-medical services provided to a patient. The rate per diagnosis proposed by hospital is greater than the agreed quality, and difference is a loss for the hospital AR Council on Health Care Standards Clinical Indicators A Users Obstetric Version 5.2 Victoria Australia [27]

In the United States in 1984 introduced the DRGs in Medicare and Medicaid programs. It decreases maternal health costs, facilitates hospital administration, and improves the quality of hospital services in gynecological obstetrics for seriously ill patients or patients with physical trauma in complications of pregnancy and childbirth at limited resources. The economic consequences are used to identify the unit costs associated with paying for cesarean delivery operations in Norwegian women and alternative methods of delivery divided whether planned births before delivery (elective) or unplanned emergency cost of cesarean delivery is greater than the non-elective type. Activity-based costing $(A B C)$ is a new method costing methodology and appeared in the 1990s. It calculates the cost price by determining the resource usage. $A B C$ method calculates the cost of recovery services in hospitals [28]. ABC is a methodology to measure the costs and financial performance for resource consumption and cost objects that can be applied in maternal health services at home regarding pregnant women's reproductive health. It calculates the patient's ability to pay for childbirth total or per unit/per patient by calculating the costs in all units/cost centers and distributing them to production units paid by patients.

\section{AR DRGs}

A DRG is a scheme or part of patients classification that was initially developed to connect the type of patient care in a hospital with costs of patient care [29], [30]. The design and development of DRGs began in the late 60s at Yale University. The primary motivation was to create a practical framework to monitor the use of hospital services. The AR National DRG (AN-DRGs) consists of the AR Case-mix Clinical Committee, a medical body that examines the implementation of DRGs in Australia. After investigating the US DRGs, the AR state concluded a need to modify the DRGs following AR standards and practices. AN-DRGs classify more than 14,000 disease codes into 667 groups.

Separation of medical and surgical procedures for the hierarchy of methods, medical problems, and other factors differentiates the treatment process. The Commonwealth of Health and Aging developed the AR Refined DRG (AR-DRG). The first step is to determine the main diagnosis category based on principal diagnosis and then separate it into surgical and medical groups. Each surgical and medical group was divided by the Automatic Interaction Detector method - subsequent 
separation based on consideration of the significance of comorbidity, complexity, or age [31].

Advantages and disadvantages of AR's Related Group's Diagnosis (DRGs) goal outcomes are below [32], [33]:

1. Service delivery will avoid overutilization, unplanned, and missed to improve the control and determine the payment methods for each patient based on diagnosis, medication, patient therapy, and length of stay

2. The system and administrative burden of fund managers and health providers will be more straightforward and less troublesome. It reduces the management costs

3. Managed care system can help doctors identify ways to improve the quality of health services in hospitals

4. The quality of patient care services increases

5. Lower patient care costs

6. Higher satisfaction of health-care professionals

7. Reducing the variation of treatments per diagnosis

8. Available data must be complete from patient entered to patient discharge

9. DRGs are a payment method for treatment at a hospital based on a diagnosis, not the utilization of medical or non-medical services provided to a patient. The amount of payment or tariff per diagnosis has been predetermined. The hospital's higher costs are more significant than the agreed tax is a loss for the hospital.

The DRGs application in Japan is very influential on hospitals' financial system through budget simulations when DRGs are used as a method of patient payment for homesick. The research examined the difference in estimated costs for a particular diagnosis, namely, stable angina pectoris, with a traditional billing system [34]. Research findings showed that non-medical factors are influenced by medical ethics inpatient health services and need to balance the obligation to protect the right of patients to avoid trauma and stress in treatment [35], [36].

\section{Methodology}

This study uses quantitative and qualitative approaches. The 42 samples are pregnant women and selected by purposive sampling techniques. Data collection is collected using secondary data, observations, interview, and focus group discussion with health workers, nurse doctors, and midwives. Data are analyzed by $A B C$ system ABC method. DRG 370 AR-DRGs model analyzes the direct cost and indirect cost, and support costs.

\section{Results and Discussion}

Update hospital was established on August 7, 1972, and located at Palu Bay. Decree of Governor of Central Sulawesi Province No.59/DH.TAP/1972 decided the health services coverage was preventive, curative, and rehabilitative. Update hospital has 31 specialist doctors, 34 general practitioners, four dentists, 313 nursing staffs, 130 nonnursing staffs, and 187 non-medical personnel. The five doctors are gynecology obstetric specialists. Update hospital has 300 beds with a bed rate of 76.6 and an average length of stay of 5 days.

Update hospital provides 347 beds, consisting of 17 beds for VIP, 74 beds for class 1, 35 beds for type 2, and 162 beds for type 3 . Intensive care unit (ICU) has 20 beds and 10 cots in the delivery room, and 5 in the operation room, and 21 in isolation room. The hospital has 31 general practitioners, 32 specialists such as neurosurgery, skin, and venereal disease, orthopedic and urology, then obstetrics and gynecology specialists (Obsgin) of three doctors and nine dentists. Update hospital received a decree from November 7 , 2016, and ended November 6, 2019, with plenary or five-star statuses. Update still needs more doctor's specialist. The local government tries to send doctors to less than one specialist in each service area, and they will collaborate with Sardjito Hospital in Yogyakarta, Wahidin Hospital Makassar, and the Faculty of Medicine Gadjah Mada University.

Secondary data was used to calculate unit costs for cesarean section services, including the number of medical devices, non-medical devices, doctors, midwives, nurses, administrative staff, and building area. The preparation of the AR (DRG's 370) relationship with MDC 14 and ICDC $X$ unit costs of cesarean patients require complete, valid, and reliable data. Comprehensive data are medical records that contain patient's identity (age, sex, and responsibility, cost, primary diagnosis, comorbidities, complications, length of stay, treatment, supporting surveillance (laboratory, ultrasound), medical service, non-medical health equipment, and doctors, nurses, and midwives service.

\section{Characteristics of Pregnant Women}

Cesarean delivery is closely related to the length of stay of the patient in the hospital, with an average of 5.5 days of treatment. The lowest treatment duration was DRGs O01D disease group with 4 days of treatment, and the highest treatment was DRG's O01A in cases of complications and comorbidities (ex-section and diabetes) with a length of treatment of 7 days, as shown in Table 1. 


\section{Table 1: DRGs distribution}

\begin{tabular}{llllll}
\hline $\begin{array}{l}\text { DRGs } \\
\text { classification (370) }\end{array}$ & $\begin{array}{l}\text { Age } \\
\text { (year) }\end{array}$ & $\begin{array}{l}\text { Length of } \\
\text { stay (day) }\end{array}$ & Percentage & $\begin{array}{l}\text { Quantity } \\
\text { (sample) }\end{array}$ & Percentage \\
\hline DRGs O01A & 35 & 7 & 31.8 & 15 & 35.7 \\
DRGs O01B & 38 & 6 & 27.3 & 10 & 23.8 \\
DRGs O01C & 35 & 5 & 22.7 & 9 & 21.4 \\
DRGs O01D & 33 & 4 & 18.2 & 8 & 19.1 \\
& 5.5 day & 100.0 & 42 & 100.0 \\
\hline \multicolumn{2}{l}{ Source; Secondary data update hospital, 2018. }
\end{tabular}

Source; Secondary data update hospital, 2018.

In Indonesia, pregnant women have "at risk" associated with pregnancy complications and childbirth, and length of stay in hospital. The management of each pregnant woman must use standard operational obstetric procedures and operations to save the mother and baby's lives. Table 1 shows the characteristics of 42 respondents. The DRG O01A contains patients with complications and comorbidities, eclampsia, diabetes, hypertension, etc. The average age is 33-38 years with a length of stay is 4-6 days. The cesarean delivery factors are influenced by age, length of stay, and hospital care costs. The average ages are 20-35 years old. The age 35 years or above is categorized as a high-risk group DRGs O01D (premature rupture of membranes, dystocia).

\section{Rate Procedures for In Hospitals}

Production costs are clinical laboratories, anatomic pathology laboratories, radiology departments, outpatient units, emergency departments, ICU units, surgical units, inpatient units, medical rehabilitation units, mortuary units, etc. The resources assigned to activities are done to manage manufacturing activities or cost objectives to meet the customer's need. All rates are based on activity. The results of resources to action are (1) identify the characteristics of charged resources, (2) method to load resources to activities (a. direct tracing, b. allocation, c. tracing driver), and (3) characteristics of resources that will be charged to activities. The final output is the transformation of resources caused by movements, and the production process is a calculation of treatment costs based on moves in two cost categories, direct and indirect costs to produce rate for cesarean operation costs per cost of DRG for each group.

The rate for cesarean delivery is determined by resource consumption about patients with DRGs complications in labor. Table 3 shows the direct cost per diagnosis of the group found the highest number cesarean section surgical procedure costs of US $\$ 26378$ indirect cost activity. The high-cost allocation is due to the high price of medical equipment, while the low cost of US\$ 387 is found in charge of the procedure to examine patients in the laboratory because not all patients need laboratory tests. The highest rate is found in the depreciation cost of building at US\$2957, and the lowest prices are electricity because surgery is only done for the emergency patient. Table 3 shows costs for DRGs.

\section{Table 2: Cost loading procedure in hospital production department}

\begin{tabular}{|c|c|c|}
\hline No. & Cost loading procedure & Direct \\
\hline A1 & Patient registration in hospital & $\begin{array}{l}\text { Cesarean surgery patients' procedure starts from the obstetric clinic or emergency department by registering patients through a } \\
\text { computerized online system that is directly connected to various medical records. Emergency patients can be registered through the } \\
\text { obstetric clinic and in the emergency department at a rate of US\$2.2. The total unit for medical services per patient is an average of } \\
\text { US\$ 17. The treatment cost for } 42 \text { patients is US\$ } 714 \text {. Total patient registration costs are US\$ } 936\end{array}$ \\
\hline B2 & $\begin{array}{l}\text { The treatment procedure of medical } \\
\text { services diagnosis for health workers }\end{array}$ & $\begin{array}{l}\text { Can calculate the midwife's medical services cost with a monthly salary of US } \$ 147 \text { with a work duration of } 37,440 \text { min to determine per } \\
\text { minute salary. The monthly wage divided by work time per minute is US } \$ 56 \text { with a consumption time of } 15 \text { min. The total compensation } \\
\text { of midwife services is US } \$ 3.7 \text {. The treatment cost of medical services for internal medicine doctors with a monthly salary of US } \$ 330 \\
\text { with a duration of work time of } 9360 / \text { min is US } \$ 477 \text {, and a per-minute salary is US } \$ 32 \text {. The total number of expert medical services is } \\
\text { US } \$ 29 \text {. Nurses and operators of central surgery have a monthly salary of US } \$ 204 \text { with a duration of work of } 9360 \text { min, consumption } \\
\text { of surgery time } 90 \text { min, and compensation per minute of US } \$ 44 \text {. The total number of cesarean surgery patients is } 42 \text { patients, and the } \\
\text { compensation received by surgical nurses is US } \$ 1848 \text {. The total cost of midwives and doctors medical services is US } \$ 7043\end{array}$ \\
\hline C3 & Laboratory procedures treatment & $\begin{array}{l}\text { Laboratory tests diagnose pre-operative patients, such as complete blood tests. The gynecological examination and USG costs } \\
\text { depend on disease type are US } \$ 9 \text {, and the treatment cost of } 42 \text { patients is US } \$ 378 \text {. Total laboratory costs are US } \$ 387 \text {. }\end{array}$ \\
\hline D4 & Pre-operative procedure & $\begin{array}{l}\text { Pre-operative care is done in the inpatient room for } 1 \text { or } 2 \text { days before surgery. Based on DRGs, the O01A group ( } 15 \text { patients) with } \\
\text { complications and comorbidities produces total cost of US } \$ 355 \text {, the O01B group (10 patients) with severe complications produces } \\
\text { total cost of US } \$ 305 \text {, the O01C group ( } 9 \text { patients) has a total cost of US } \$ 265 \text {, and O01D group ( } 8 \text { patients) makes the total cost } \\
\text { US } \$ 160 \text {. The pre-operative preparation costs are US } \$ 1124\end{array}$ \\
\hline E5 & Treatment for cesarean section surgery & $\begin{array}{l}\text { Surgical cesarean section costs for overhead costs and single usage medical materials are US\$226. The total overhead cost for } \\
\text { the production unit is US } \$ 249 \text {, for the hematological set is US } \$ 14955 \text { at } 5 \text { years of medical life at the value of US } \$ 300 \text {. Infusion } \\
\text { equipment is US\$ } 18 \text { with an economic age of } 5 \text { years with a value of US\$ } \$ 5 \text {. The supporting equipment for two operating lights is } \\
\text { US } \$ 8814 \text { at an economical period of } 5 \text { years of US } \$ 1763 \text {. Total costs are US } \$ 26378\end{array}$ \\
\hline \multirow[t]{2}{*}{ F6 } & Treatment for patient care procedures & $\begin{array}{l}\text { The anesthetics, analgesics and uterotonic drugs, and intravenous fluids usage in the post-operative stage are started from the } 2^{\text {nd }} \\
\text { day for emergencies. Post-operative drug costs for DRGs O01 A group (15 patients) are US } \$ 355 \text { with an average cost treatment for } \\
\text { each patient is US } \$ 35 \text {, DRGs O01B group (10 patients) is US } \$ 305 \text { with a cost treatment US } \$ 31 \text {, DRGs O01C group ( } 9 \text { patients) } \\
\text { is US } \$ 265 \text { with a treatment cost is US } \$ 30 \text {. The unit cost of DRGs O01D group (8 patients) is US\$ } \$ 160 \text {, and the cost of treatment is } \\
\text { US } \$ 20 \text {. The total price is US } \$ 1085 \text {, and maternal nutrition's total cost is US } \$ 60\end{array}$ \\
\hline & & Indirect \\
\hline A1 & Building & $\begin{array}{l}\text { Building costs are indirect costs that cannot be covered by cost objects. For obstetric emergency rooms with a total area of } 228 \mathrm{~m}^{2} \text {, } \\
\text { the land price is US } \$ 84 \text { for } 1 \text {-year depreciation, the cost for patients is US } \$ 1.4 \text {. The overhead costs of } 15 \text { medical devices } \\
\text { include emergency room polyclinic building, obstetric gynecology room, obstetric care, infant care, pharmacy, laboratory and } \\
\text { radiology installation, nutrition installation, washing/laundry installation, water installation, space mortuary, housekeeping, car park, } \\
\text { ambulance, and mosque. The cost for the land area of } 7033 \mathrm{~m}^{2} \text { is US } \$ 2601\end{array}$ \\
\hline B2 & Electricity & $\begin{array}{l}\text { The } 15 \text { production departments need } 9310 \text { kilowatts of electricity at the cost of US } \$ 602 \text {, and a rate per watt is US } \$ 10 \text {. It requires } \\
2500 \text { watts with a charge of US } \$ 159 \text {. Electricity usage for one cesarean patient is charged US\$2.5 }\end{array}$ \\
\hline C3 & Phone & $\begin{array}{l}\text { The central medical unit uses } 60 \text { talks valued at US\$ } \$ \text {. A total of } 30 \text { days of talks need US\$150. The ambulances are used } 300 \\
\text { times a month at the cost of US\$1461 }\end{array}$ \\
\hline D4 & Sanitation and waste & $\begin{array}{l}\text { The cost of sanitation and waste is calculated by the consumption of several liters of water per day for laundry } 400 \text { liters/per } 5 \text { days, } \\
1 \text { liter of water on an average price of US } \$ 1 \times 400 \text { liters } / 5 \text { days, the total cost of US } \$ 2048 \text {. The water cost for } 42 \text { patients is US } \$ 48\end{array}$ \\
\hline E5 & $\begin{array}{l}\text { Maintenance of hospital resource } \\
\text { production department }\end{array}$ & $\begin{array}{l}\text { The overhead area of } 600 \mathrm{~m} \text { is charged in US } \$ 1750 \text {. The direct costs of } 15 \text { departmental production units in the hospital are } \\
\text { US } \$ 8353 \text {, and the average price of } 42 \text { patients is US } \$ 199 \text {. The total recapitulation cost of direct costs and indirect costs in the } \\
\text { production department is US } \$ 17,427 \text {, as shown in Table } 4\end{array}$ \\
\hline
\end{tabular}


Table 4 shows that the rate per diagnosis is related to groups. Forty-two respondents calculate the prospect payment system based on the use of hospital resource consumption for cost treatment. The average patient rate for a cesarean section is US\$ 169. The highest first category payment for DRG O01A complications and comorbidities is US\$ 2639. The high cost is due to the use of different consumption of resources such as drugs, examinations laboratories, doctor's medical services, classrooms, or VIPs.

Table 3: Direct and indirect costs at the production department

\begin{tabular}{lll}
\hline No. & Direct cost & Treatment cost (US\$) \\
\hline A1 & Patient registration procedure & 1218 \\
B2 & $\begin{array}{l}\text { Diagnostic enforcement procedures include the medical } \\
\text { services of doctors, midwives, and central surgery }\end{array}$ & 7043 \\
& $\begin{array}{l}\text { operators } \\
\text { C3 }\end{array}$ & Laboratory procedures \\
D4 & Pre-operative preparation procedure & 387 \\
E5 & Surgical procedure for cesarean section & 1124 \\
F6 & Patient's post-operative care procedure & 26378 \\
& Indirect cost & 1085 \\
A1 & Building depreciation & 2957 \\
B2 & Electricity & 774 \\
C3 & Phone & 1616 \\
D4 & Sanitation and waste/water & 2048 \\
E5 & Maintenance department of hospital resource production & 10,032 \\
& Total cost & US $\$ 17,427$ \\
\hline Source: Update hospital secondary data 2019.
\end{tabular}

In comparison, the second category, the lowest in mild complications in OGDD DRG, is US\$1251. A study in Norway and America showed a cesarean section from an economic aspect and resource consumption with a cost reduction above $15 \%$ because they insurance. Figure 1 shows the comparison of cesarean operation.

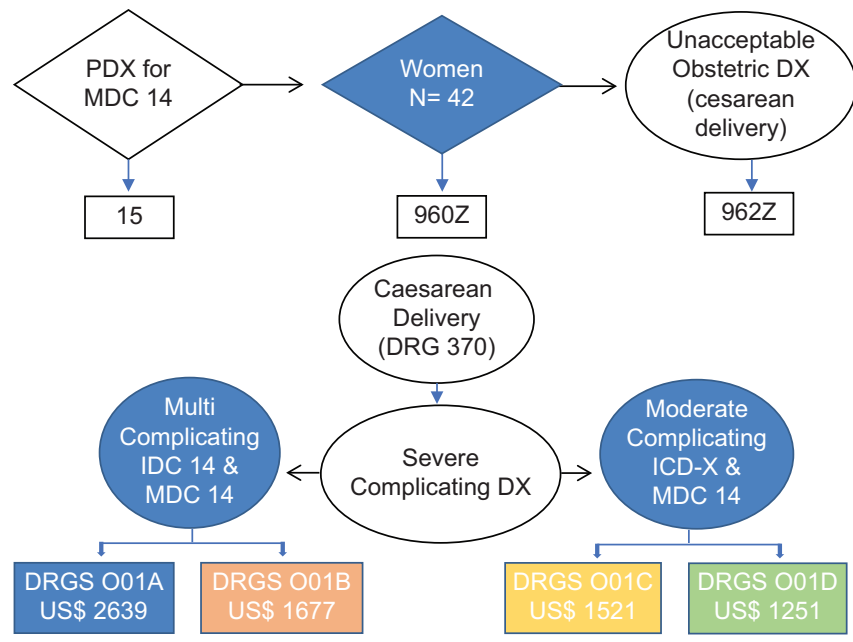

Figure 1: Comparison of cesarean operation costs

Analysis of DRG transition cost based on AN-AR DRGs 370 values for complicated and accompanying DRGs O01A has a total cost of US\$2639, and DRGs O01B group (severe complication) has a total cost of US\$ 1677. DRGs O01C group (moderate difficulties) has a total cost of US\$1521, the DRGs O01D group (mild complications) has a total cost of US\$1251, and then DRGs O01A-DRGs O01D has a total cost of US\$ 7088. DRGs group analysis shows that OGSA DRGs have a high total price than others. This is because the number of patients suffering from pregnancy complications is high, and the cost of resource consumption (laboratory medicines, medical services, doctors, and other supporting factors) is different from other disease groups. Figure 2 shows the comparison of labor costs per average cost per DRG.Transition DRGs as Prospects for Health System Payment.

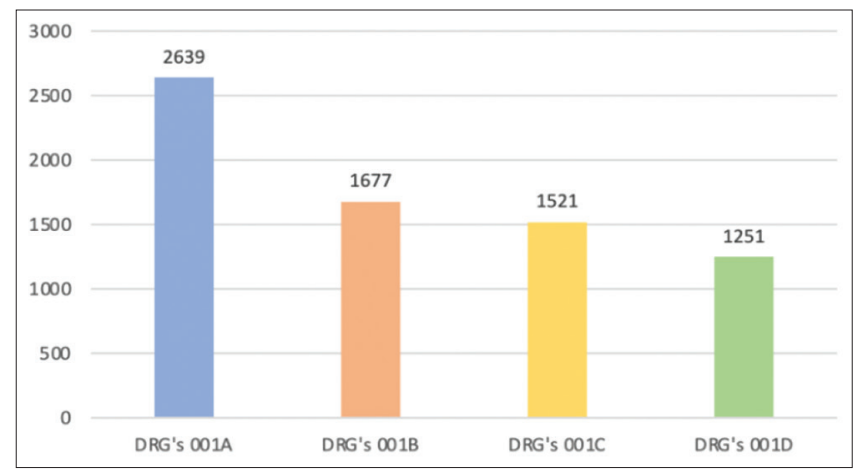

Figure 2: Comparison of patient costs based on DRGs O01A-O01D in US\$. Source: Secondary Data of Update Hospital, 2019

Figure 2 shows the cost comparison of cesarean section surgery of emergency type with AR-DRGs 370 structural model and moderate complication DX cost group shows the comparison of US\$2639 to multidifficulty. The results show that DRGs O01D group is charged US\$ 1251. The cost comparison shows the different resource allocation costs such as medicine, nutrition, laboratory, doctor's medical services, and other supporting factors. Cesarean section (PDX for MDC) and ICDC 10 [35] that consist of severe complication DX, divided into two parts, multicomplication $D X$ and moderate complication DX). The magnitude of the AR AN-DRGs model's diagnostic payment is calculated based on cost treatment from DRG001A-DRGs O01D with a total average cost of patients paying cesarean section US\$ 169 for 42 respondents in the study sample. The cost of cesarean section surgery can be controlled by fewer hospital costs than the agreed tariff, and the difference is in hospital profits. The DRGs system was first introduced in the United States in 1984 at Medicare and Medicaid programs to optimize health costs control, cost of patient care, and improve hospital services quality. This study found that the case above does not affect the cesarean delivery procedure's steps but is determined by operational costs of hospital postoperative resource consumption in the treatment room.

This study found a way to pay hospital treatment based on a diagnosis, not based on the utilization of medical and non-medical services provided to patients can see the payment system with AR-DRGs 370 model structure in Figure 1. It describes the DRG transition as a payment system for patient costs per disease diagnosis. Australia's health system model DRGs (370) with price per DRGs shows a change of DRGs from fee-for-service to Prospective Payment System (PPS). It means that payment system to health service providers in an amount determined before service provided without seeing medicinal actions or the length of hospital treatment. One form of PPS is the DRGs 
Table 4: Costs for DRGs (US\$)

\begin{tabular}{|c|c|c|c|c|c|c|}
\hline Emergency type of DRGs Australia & $\begin{array}{l}\text { International classification } \\
\text { of disease (ICD X) }\end{array}$ & $\begin{array}{l}\text { Principal diagnostic } \\
\text { group MDC } 14\end{array}$ & DRGs classification & Respondents & Percentage & Cost per DRGs (US\$) \\
\hline DRGs O01A (accompanying & Z39\&E14.9 & MDC 14 & Former SC+Diabetes & 2 & 13.34 & 327 \\
\hline \multirow[t]{7}{*}{ complication) } & Z39\&D45.9 & MDC 14 & Former Scams & 1 & 6.67 & 189 \\
\hline & Z39\&E10 & MDC 14 & Former $\mathrm{SC}+$ Hypertension & 2 & 13.34 & 328 \\
\hline & O44.1\&E14.9 & MDC 14 & Placenta previa+Diabetes & 2 & 13.4 & 327 \\
\hline & O441\&J45.9 & MDC 14 & Placenta previa+asma & 1 & 6.67 & 156 \\
\hline & O40\&J45.6 & MDC14 & Post-term pregnancy+Anemia & 1 & 6.67 & 164 \\
\hline & $015 \& 110$ & MDC 14 & Hypertension+Eclampsia & 4 & 26.67 & 665 \\
\hline & $014 \& 110$ & MDC 14 & Preeclampsia+Hypertension & 2 & 13.34 & 483 \\
\hline Total cost & & & & 15 & 100.0 & 2639 \\
\hline \multirow[t]{4}{*}{ DRGs O01B (severe complications) } & 015.10 & MDC 14 & Eclampsia & 1 & 10.00 & 173 \\
\hline & & MDC 14 & Pre-eclampsia & 5 & 50.00 & 839 \\
\hline & & MDC 14 & Placenta previa & 3 & 30.00 & 496 \\
\hline & & MDC 14 & Solution Placenta & 1 & 10.0 & 169 \\
\hline Total cost & & & & 10 & 100.0 & 1677 \\
\hline \multirow{3}{*}{$\begin{array}{l}\text { DRGs O01C (moderate } \\
\text { complication) }\end{array}$} & O 48 & MDC 14 & Post-term pregnancy & 1 & 11.12 & 169 \\
\hline & & MDC 14 & Rupture uteri & 4 & 44.44 & 676 \\
\hline & & MDC 14 & Former SC & 4 & 44.44 & 676 \\
\hline Total cost & & & & 9 & 100.0 & 1521 \\
\hline \multirow[t]{2}{*}{ DRGs O01D (mild complication) } & & MDC 14 & $\begin{array}{l}\text { Premature rupture of } \\
\text { membranes }\end{array}$ & 5 & 62.5 & 782 \\
\hline & & MDC 14 & Dystocia & 3 & 37.5 & 469 \\
\hline Total DRGs cost for 42 patients & & & & 8 & 100.0 & 1251US $\$ 7088 /$ US $\$ 169$ \\
\hline
\end{tabular}

as a determinant of payment system for patient care in hospitals.

\section{Conclusions}

DRGs transition as a Payment System Prospect affected by Australia's DRGs (370) determines the ability to pay for a patient hospital that has been agreed with the hospital as a result of cost-effectiveness. Hospitals that can control costs and quality of services better and more professional can be applied in government and private hospitals in Indonesia because patients can pay lower hospital rates and medical services, and hospitals get the benefit. Payment of hospital treatment based on DRGs is a way to pay hospital treatment based on diagnosis, not price based on the utilization of medical and non-medical services provided to a patient. This study recommends that hospital should identify the improvement efforts and clinical monitoring to ensure that changes in transition DRGs PPS do not harm patient outcomes, and this method to be used as a quality measurement of adequate medical services to Medicare patients for the hospital in Indonesia.

\section{Acknowledgment}

The researchers thank to the director, head, and staff of the nursing department, and head and staff of the Medical Record Division of the Undata General Hospital, and all parties who have provided assistance in the implementation process until the completion of this research. The acknowledgment is also to the Faculty of Medicine Tadulako University, which has funded this research.

\section{References}

1. Agan TU, Monjok E, Akpan UB, Omoronyia OE, Ekabua JE. Trend and causes of maternal mortality in a Nigerian tertiary hospital: A 5-year retrospective study (2010-2014) at the University of Calabar Teaching Hospital, Calabar, Nigeria. Open Access Maced J Med Sci. 2018;6(6):1153-8. https://doi. org/10.3889/oamjms.2018.22029983819

2. Kioupi V, Voulvoulis N. Sustainable development goals (SDGs): Assessing the contribution of higher education programmes. Sustainability. 2020;12(17):6701. https://doi.org/10.3390/ su12176701

3. Rant MB. Sustainable development goals (SDGs), leadership and Sadhguru: SELF-TRANSFORMATION becoming the aim of leadership development. Int J Manag Educ. 2020;18(3):100426. https://doi.org/10.1016/j.jjme.2020.100426

4. Kamiński M, Łoniewski I, Łoniewska B. Google, is caesarean section good for me? The global Internet searches associated with mode of birth methods: Retrospective analysis of google trends data. Midwifery. 2020;89:102787. https://doi. org/10.1016/j.midw.2020.102787

5. Sarkar S. Prevalence and determinants of the use of caesarean section (CS) in the dichotomy of "public" and "private" health facilities in West Bengal, India. Clin Epidemiol Glob Health. 2020;8(4):1377-83. https://doi.org/10.1016/j.cegh.2020.05.017

6. Chan MH, Hauck Y, Kuliukas L, Lewis L. Women's experiences of their involvement around care decisions during a subsequent pregnancy after a previous caesarean birth in Western Australia. Women Birth. 2020;2020:S1871519220303255. https://doi. org/10.1016/j.wombi.2020.09.007 PMid:33004288

7. Vogel JP, Betrán AP, Vindevoghel N, Souza JP, Torloni MR, Zhang J, etal. Use ofthe Robson classification to assess caesarean section trends in 21 countries: A secondary analysis of two WHO multicountry surveys. Lancet Glob Health. 2015;3(5):e260-70. https://doi.org/10.1016/s2214-109x(15)70094-x PMid:25866355

8. Fawcus S, Moodley J. Postpartum haemorhage associated with caesarean section and caesarean hysterectomy. Best Pract Res Clin Obstet Gynaecol. 2013;27(2):233-49. https://doi. org/10.1016/j.bpobgyn.2012.08.018 PMid:23084097

9. Grytten J, Skau I, Sørensen R. Do expert patients get better treatment than others? Agency discrimination and statistical 
discrimination in obstetrics. J Health Econ. 2011;30(1):163-80. https://doi.org/10.1016/j.jhealeco.2010.10.004 PMid:21095034

10. Zhou YB, Li HT, Si KY, Zhang YL, Wang LL, Liu JM. Association of elective cesarean delivery with metabolic measures in childhood: A prospective cohort study in China. Nutrition, Metab Cardiovasc Dis. 2019;29(8):775-82. https://doi.org/10.1016/j. numecd.2019.04.007

PMid:31151881

11. Junqueira $M E$, de Oliveira $C T$, Tone $L G$, de $M$ Lee $M L$, de Andréa ML, Bruniera $P$, et al. Caesarean sections, prenatal and postnatal conditions and childhood acute lymphoblastic leukaemia: A case-control study in the State of São Paulo, Brazil. Cancer Epidemiol. 2020;69:101851. https://doi.org/10.1016/j. numecd.2019.04.007

PMId:33186820

12. Carolan M. Gestational diabetes mellitus among women born in South East Asia: A review of the evidence. Midwifery. 2013;29(9):1019-26. https://doi.org/10.1016/j. midw.2012.09.003

PMid:23415355

13. Sindiani A, Rawashdeh $\mathrm{H}$, Obeidat $\mathrm{N}$, Zayed $\mathrm{F}$, Alhowary AA. Factors that influenced pregnant women with one previous caesarean section regarding their mode of delivery. Ann Med Surg. 2020;55:124-30. https://doi.org/10.1016/j. amsu.2020.05.007 PMid:32477510

14. Shen M, Li L. Differences in Cesarean section rates by fetal sex among Chinese women in the United States: Does Chinese culture play a role? Econ Hum Biol. 2020;36:100824. https://doi. org/10.1016/j.ehb.2019.100824

PMid:31675612

15. Fatimah YA, Govindan K, Murniningsih R, Setiawan A. Industry 4.0 based sustainable circular economy approach for smart waste management system to achieve sustainable development goals: A case study of Indonesia. J Cleaner Prod. 2020;269:122263. https://doi.org/10.1016/j.jclepro.2020.122263

16. Odagiri M, Cronin AA, Thomas A, Kurniawan MA, Zainal M, Setiabudi W, et al. Achieving the sustainable development goals for water and sanitation in Indonesia results from a five-year (2013-2017) large-scale effectiveness evaluation. Int J Hyg Environ Health. 2020;230:113584. https://doi.org/10.1016/j. ijheh.2020.113584

17. Boker F, Alzahrani A, Alsaeed A, Alzhrani M, Albar R. Cesarean section and development of childhood bronchial asthma: Is there a risk? Open Access Maced J Med Sci. 2019;7(3):347-51. https://doi.org/10.3889/oamjms.2019.085

PMid:30833999

18. Taha Z, Hassan AA, Wikkeling-Scott L, Papandreou D. Risk factors associated with initiation of breastfeeding among mothers with low birth weight babies: A cross-sectional multicenter study in Abu Dhabi, United Arab Emirates. Open Access Maced J Med Sci. 2020;8(B):38-44. https://doi.org/10.3889/oamjms.2020.3867

19. Sukmawati S, Sunarno I, Arsyad MA, Idris I. Vaginal and cesarean section delivery with severe preeclampsia and preeclampsia with complications. Enferm Clín. 2020;30:537-40. https://doi.org/10.1016/j.enfcli.2019.07.155 PMid:32204231

20. Hasanova R, Mentzakis E, Paolucci F, Shmueli A. Beyond DRG: The effect of socio-economic indicators on inpatient resource allocation in Australia. Health Pol Technol. 2018;7(3):302-9. https://doi.org/10.1016/j.hlpt.2018.07.001

21. Ghaffari S, Jackson TJ, Doran CM, Wilson A, Aisbett C. Describing Iranian hospital activity using Australian refined DRGs: A case study of the Iranian social security organisation. Health Policy. 200;87(1):63-71. https://doi.org/10.1016/j. healthpol.2007.09.014

22. Blencowe H, Cousens S, Oestergaard MZ, Chou D, Moller AB, Narwal R, et al. National, regional, and worldwide estimates of preterm birth rates in the year 2010 with time trends since 1990 for selected countries: A systematic analysis and implications. Lancet. 2012;379(9832):2162-72. https://doi.org/10.1016/ s0140-6736(12)60820-4

PMid:22682464

23. Sahlin M, Wiklund I, Andolf E, Löfgren M, Carlander AK. An undesired life event': A retrospective interview study of Swedish women's experiences of caesarean section in the 1970s and 1980s. Sex Reprod Healthc. 2021;27:100581.

PMid:33310653

24. Wen J, Yu G, Kong Y, Liu F, Wei H. An exploration of the breastfeeding behaviors of women after cesarean section: A qualitative study. Int J Nurs Sci. 2020;7(4):419-26.

PMid:33195754

25. Jabs C, Giroux M, Minion J, Karreman E, Faires $M$ Evaluation Of adjunctive azithromycin prophylaxis in women undergoing caesarean delivery in a setting with low baseline incidence of surgical site infection. J Obstet Gynaecol Can. 2021;2020:S1701216320310380. https://doi.org/10.1016/j. jogc.2020.12.016

PMid:33412302

26. Hensher M. Incorporating environmental impacts into the economic evaluation of health care systems: Perspectives from ecological economics. Resour Conserv Recycling. 2020;154:104623. https://doi.org/10.1016/j. resconrec.2019.104623

27. Driscoll A, Hinde S, Harrison A, Bojke L, Doherty P. Estimating the health loss due to poor engagement with cardiac rehabilitation in Australia. Int J Cardiol. 2020;317:7-12. https:// doi.org/10.1016/j.ijcard.2020.04.088

28. Tewfik K, Chiarelli P Copelli C, Pederneschi N, Cassano L, Manfuso A, et al. Italian cost analysis of free flap surgery in head and neck reconstruction using the activity-based costing (ABC). J Plast Reconstr Aesthet Surg. 2020;2020:S1748681520305933. https://doi.org/10.1016/j.bjps.2020.10.096 PMid:33279430

29. Fouad J, Joseph P. The evolution in nomenclature, diagnosis, and classification of pulmonary hypertension. Clin Chest Med. 2021;2021:S0272523120301246. PMid:33541603

30. Sinha N, Das A. Automatic diagnosis of cardiac arrhythmias based on three stage feature fusion and classification model using DWT. Biomed Sig Proc Control. 2020;62:102066. https:// doi.org/10.1016/j.bspc.2020.102066

31. Dehghan-Manshadi A, Yu P, Dargusch M, StJohn D, Qian M. Metal injection moulding of surgical tools, biomaterials and medical devices: A review. Powder Technol. 2020;364:189-204. https://doi.org/10.1016/j.powtec.2020.01.073

32. Kou K, Dasgupta P, Aitken JE, Baade PD. Impact of area-level socioeconomic status and accessibility to treatment on life expectancy after a cancer diagnosis in Queensland, Australia. Cancer Epidemiol. 2020;69:101803. https://doi.org/10.1016/j. canep.2020.101803 PMid:32927295

33. Tervonen HE, Aranda S, Roder D, Walton R, Baker D, You H, et al. Differences in impact of aboriginal and Torres Strait islander status on cancer stage and survival by level of socio-economic disadvantage and remoteness of residence a population-based cohort study in Australia. Cancer Epidemiol. 2016;41:132-8. https://doi.org/10.1016/j.canep.2016.02.006 PMid:26953842

34. Hamada H, Sekimoto M, Imanaka Y. Effects of the per diem 
prospective payment system with DRG-like grouping system (DPC/PDPS) on resource usage and healthcare quality in Japan. Health Policy. 2012;107(2-3):194-201. https://doi. org/10.1016/j.healthpol.2012.01.002

PMid:22277879

35. Seo AR, Song H, Lee WJ, Park KN, Moon J, Kim D. Factors associated with delay of emergency medical services activation in patients with acute stroke. J Stroke
Cerebrovasc Dis. 2021;30(1):105426. https://doi.org/10.1016/j. jstrokecerebrovasdis.2020.105426

PMid:33161352

36. Allard $\mathrm{CT}$, Krasowski MD. Data on the activation and utilization of an electronic health record patient portal in an adult inpatient population at an academic medical center. Data Brief. 2021;2021:106806. https://doi.org/10.1016/j.dib.2021.106806 PMid:33604427 